\title{
POSSIBILITIES FOR ADDITION OF NANOSIZED PARTICLES IN GAS METAL ARC WELDING
}

\author{
Plamen Tashev \\ Institute of Metal Science, Equipment and Technologies \\ with Hydro- and Aerodynamics Center "Acad. A. Balevski", \\ Bulgarian Academy of Sciences, \\ 67, "Shipchenski Prohod" St., 1574 Sofia, Bulgaria, \\ e-mail: ptashev@ims.bas.bg
}

\begin{abstract}
The possibilities and the technological features of Gas Metal Arc Welding (GMAW) are considered in detail. The problems arising from the addition of nanosized particles in the liquid phase are analyzed from the point of view of the possibilities of the welding process. Possible methods of adding nanosized particles to the weld metal in GMAW are presented. Welded joints are obtained by active GMAW process, with nanosized particles added following specially developed methodology. The test specimens obtained from the welded joints are subjected to microhardness tests and metallographic tests. Conclusions are made about the influence of the nanoparticles on the properties of the modified metal.

Keywords: welding, overlay welding, nanomodified weld metal, nanoparticles, nano diamonds, chrome coating, TiN, GMAW, cored wire, hardness, microhardness, metallography, wear resistance.
\end{abstract}

\section{INTRODUCTION}

The modern welding industry in its different areas leads to the necessity for joining and overlaying materials with high strength, hardness, wear resistance, corrosion resistance and a number of other special properties. The nanomaterials and their related technologies are a possible solution to the problem. A new scientific trend is intensely developed, which is related to investigations on the use of nanosized refractory materials as modifying additives in order to refine the structure of the metal alloys and to enhance their mechanical and other properties [1-4]. It is hypothesized that the introduction of NanoParticles (NPs) in the liquid metal results in formation of a self-organizing dispersed

DOI: 10.7546/EngSci.LVIII.21.01.03

Engineering Sciences, LVIII, 2021, No. 1 
system. The solid particle with its surrounding absorption layer serves as a core of the microvolumes of the suspension. Thus, a heterogeneous system is created, in which concentration supercooling occurs in the volume, which can significantly change the process of structure formation and the properties of the obtained metal. In the process of crystallization, the NPs serve as centers for the formation of solid phase. An activated transition layer (Fe or $\mathrm{Cr}$ for iron-based alloys and $\mathrm{Cu}, \mathrm{Al}$ and $\mathrm{Ag}$ for aluminum-based alloys) is usually applied on the NPs surface, which ensures good wetting of the particles by the melt and can provide conditions for solid phase growth at relatively low overcooling. It is of great importance for the industry to study and master the possibilities for introduction of refractory NPs in the weld metal during the processes of Gas Metal Arc Welding (GMAW).

\section{TECHNOLOGICAL FEATURES OF GMAW}

The GMAW, also known as MIG/MAG welding, is a technological process in which the source of heat energy is an electric arc that burns between the melting electrode (i.e., usually wire pre-wound on a roll and fed mechanized with a wire feeder) and the welded product. The wire, the welding pool and the hot metal are protected against the harmful atmosphere influence by shielding environment [5] of inert gas in the case of MIG welding, and active gas, interacting with the metal in the case of MAG welding, Fig. 1.

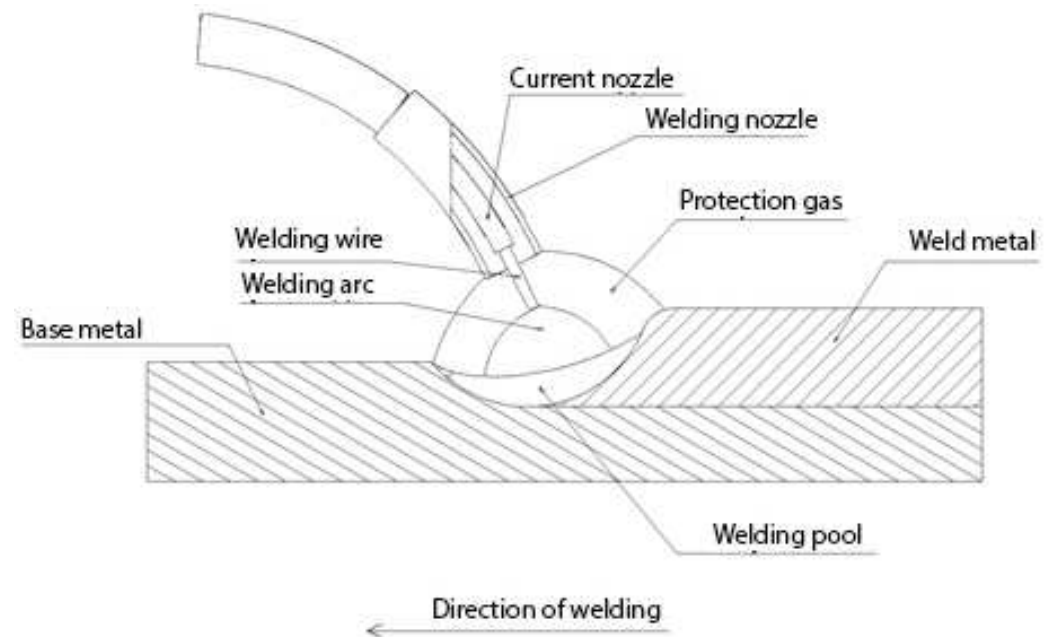

Fig. 1. Scheme of MIG/MAG welding 
The welding wires are either solid, or tubular. The welding with solid melting wire in inert gas protection environment is designated as process 131, and that in active gas protection environment is designated as process 135 (BSS EN ISO 4063). The welding with tubular melting wire in inert gas protection environment is designated as process 132, and that in active gas environment is designated as process 136 . The process of welding with selfprotected wire without protection gas is designated as process 114 .

The most commonly used current source is constant current one with a steady characteristic, which provides constant voltage with reverse polarity (plus on the electrode).

The field of application for steels and non-ferrous metals determines the choice of the combination wire-protective gas. Steels are welded only with active protective gases and non-ferrous metals are welded with inert protective gases.

MIG/MAG-welding is the most common industrial welding process, preferred because of its versatility, high welding speed and the suitability for relatively easy mechanization, automation or robotization. This process is widely used in the automotive industry. MIG/MAG welding is rarely used in open spaces exposed to wind (air flow velocity $>1 \mathrm{~m} / \mathrm{s}$ ). This multiplies the effect of the possible application of technologies to improve the properties of the weld, including by modifying the weld metal with nanosized particles.

For solid wires, the most commonly used diameters are $0.8,1.2$ and $1.6 \mathrm{~mm}$. Most often the wires have copper coating providing good electrical contact with the power supply nozzle and good corrosion resistance. The copper coating provides the possibility to add nanosized particles in the welding pool aimed to improve the process of welding or to modify the liquid metal.

The following protective gases are used: in MAG welding most often mixtures of argon and $\mathrm{CO}_{2}(5-20 \%)$ to provide good penetration, steady arc and very few splashes. The addition of $5 \%$ oxygen enhances the jet transfer but the presence of excessive oxygen oxidizes the wire, which can possibly result in formation of pores in the overlay metal in case the wire does not contain enough deoxidizers. The pure $\mathrm{CO}_{2}$ provides welds with deep penetration but enhances the formation of oxide, which affect adversely the mechanical properties of the weld and leads to release of many splashes.

In MIG-welding the inert gases used are argon or helium and sometimes mixtures thereof. The higher percentages of helium improve the speed of welding and the quality of the joint in welding of aluminum. Hydrogen added in small quantities (up to 5\%) to argon is used for welding nickel. Higher concentrations of hydrogen (up to $25 \%$ ) are used for welding conductive ma-

Engineering Sciences, LVIII, 2021, No. 1 
terials as copper. Hydrogen should not be used in welding steel, aluminum or magnesium due to the risk of hydrogen embrittlement.

The availability of such a wide variety of gases and their mixtures makes it significantly more difficult to select suitable nanosized particles for modification of the liquid metal. The main parameters of GMAW, which significantly influence the process of modification, are:

- Wire feed rate, which determines the welding current;

- Arc voltage;

- Electrode extension;

- Welding/travel speed;

- Tilt angle of the welding torch;

- Type and diameter of wire;

- Composition of protective gas (if relevant).

The advantages of the method GMAW are the possibility to join parts of different materials with a wide range of thickness, high productivity (increased even more when using tubular wire), and continuous feeding of wire with no necessity to change the electrodes. Moreover, the process allows a high extent of automation and robotics. The main disadvantage is related to the relatively limited range of consumables.

\section{INTRODUCTION OF NPS IN THE LIQUID PHASE DEPENDING ON THE SPECIAL FEATURES OF THE PROCESS}

As with other welding processes, the introduction of NPs in the liquid phase is associated with overcoming a number of difficulties. Theoretically, NPs can be pre-introduced into the composition of the electrode wire or in its coating. The introduction on the electrode wire can be carried out on the stage of its manufacture but that would be a complicated and expensive technology. A reasonable way is to embed or coat the NPs in the area where the weld will be performed. When using a tubular wire, it is easier to add NPs to some component of the filling. It is necessary to analyze the functions and the properties of the components and to select the most appropriate for the purpose.

The technologies for immediate application of the added NPs on the surface in overlay welding using binders are also possible. In order to increase the concentration of NPs in the overlay material and to "hide" the NPs from the direct impact of the heat source, we have developed technologies for pre-forming 

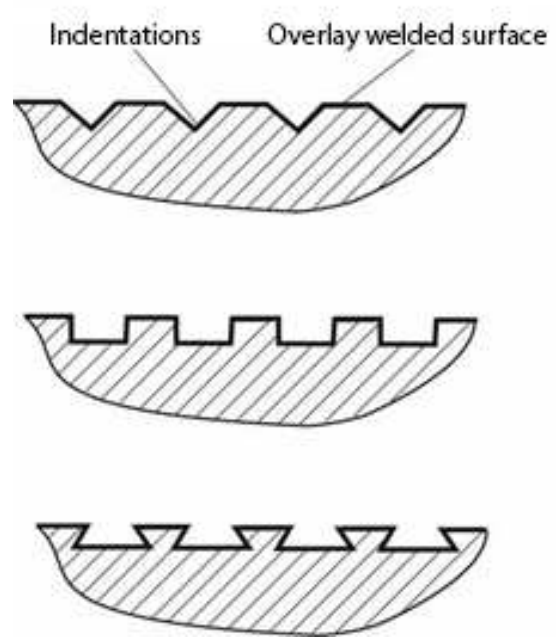

Fig. 2. Shapes of the indentations in overlay welding

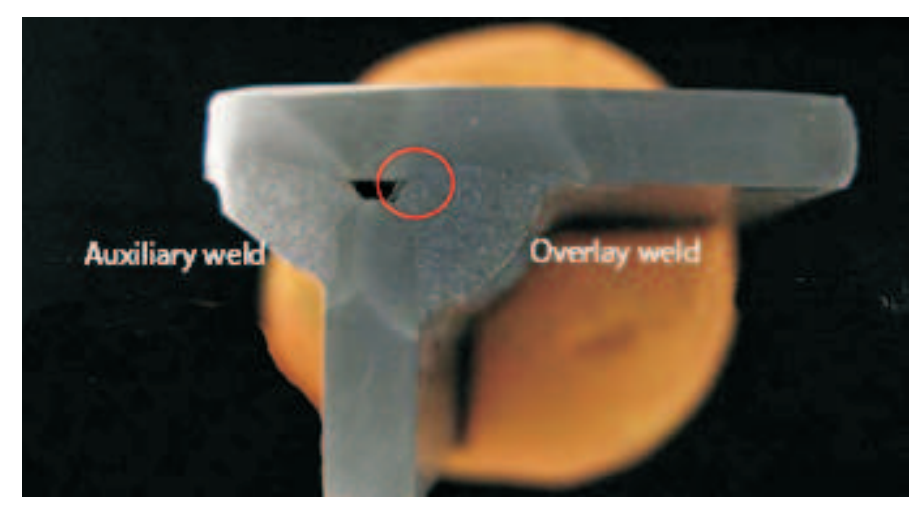

Fig. 3. General view of overlay weld joint

of indentations on the surface in the places to be welded (Figs 2 and 3) [6].

Increasing the productivity of the process in MIG welding and development of technologies for the production of new modifications of welding electrode materials with nanostructured particles is a promising innovative area of research in welding production.

The traditional MIG welding ensures steady formation and good quality of the weld, hence the weld joint. As the current density and the welding speed increase, the stability of the seam formation decreases. 
The use of tubular wires improves the formation of weld and increases the efficiency of welding. The disadvantage of the tubular wires is the high cost.

The arc burning and weld formation can be improved by application of NPs on the surface of solid wires with filling factor of only $0.02-1.5 \%$ [7], as well as by adding activating admixtures with concentration $0.01-0.003 \%$ in the metal [8].

The technological problems can be solved and the productivity of MIG welding can be increased through the use of activating fluxes [9].

The unevenness of the layer, the losses of flux due to scattering and evaporation lead to unstable introduction of activating substances in the welding zone and therefore this method is not effective in MIG/MAG welding and is mainly used in Tungsten Inert Gas welding (process 141).

The efficiency can also be improved by changing the surface properties of the welding materials by means of a microcomposite coating of ultrafine activating flux and a metal matrix of copper, nickel or iron. The coating is a dimensionless microcomposite [10].

Of particular interest is the study of Dr. S. Parshin and Dr.-Ing. G. Bürkner [11], aimed to development of efficient technology for forced MIG welding with high productivity, based on the creation of nanostructured welding electrode materials with composite coating of ultra-fine activating fluxes. The basis for manufacture of activated wires is welding wire G4Si1 according to DIN EN 440 with diameter $1.2 \mathrm{~mm}$. The electrochemical deposition of activating fluxes on the surface of the welding wires is performed from colloidal copper electrolytes with ultrafine flux particles with a size of $0.01-1 \mu \mathrm{m}$.

For the purposes of the research, seven types of activated wires with composite coatings with copper matrix were made. The droplet transition was studied during overlay welding of rotating tube using a video camera. Welding current and arc voltage were measured. The studies on weld formation were carried out during overlay welding on S235JR steel plates with thickness 6-8 mm.

The following characteristics are studied: change of the arc voltage and strength of the welding current; change of dimensions of welds; process of melting of the electrode metal. Increased productivity in MIG welding has been achieved using new composite welding materials in the form of nanostructured electrode wires with microcomposite coating of particles of activating fluxes and metal matrix. This technology for forced MIG welding makes it possible to change the thermophysical properties of the welding arc and improve the melting process of metals. At the same time, the productivity of the welding process is increased by increasing the depth of penetration and changing the 
design of the welded joint. Moreover, the labor costs for cutting and processing the edges in sheet structures with a large thickness are reduced.

\section{EXPERIMENTS FOR APPLICATION OF WELDS WITH DIRECT ADDITION OF NPS}

The diamond NPs have specific surface area of about $300 \mathrm{~m}^{2} / \mathrm{g}[12,13]$ and structure with characteristic features [14], which determine their high adsorption properties. The method of obtaining diamond NPs has a significant impact on their properties. NPs obtained by detonation synthesis are purified according to a rather complex scheme [15]. Electrosonic and electromagnetic methods are used for activation of the diamond NPs.

The specimens for overlay welding and testing are T-shaped fillet welds (Fig. 3) with a deliberately separated cavity in the area of the weld root.

A certain quantity of NPs is placed in the cavity thus separated. The purpose of the cavity is to protect the NPs from the direct impact of the arc until they enter the melt. This way of modifying the melt implies a higher concentration of NPs in the root of the weld and is an innovative approach with possible application in other welding methods.

Experiments have been carried out for direct introduction of the diamond NPs in the cavity thus formed [16]. In Figure 4 a corner weld joint with NPs added to the weld metal is shown. The resulting joints are cut transversely to the weld in three characteristic areas of which two at a certain distance from both ends and one in the middle of the weld. Metallographic specimens are obtained from the samples prepared by means of standard metallography

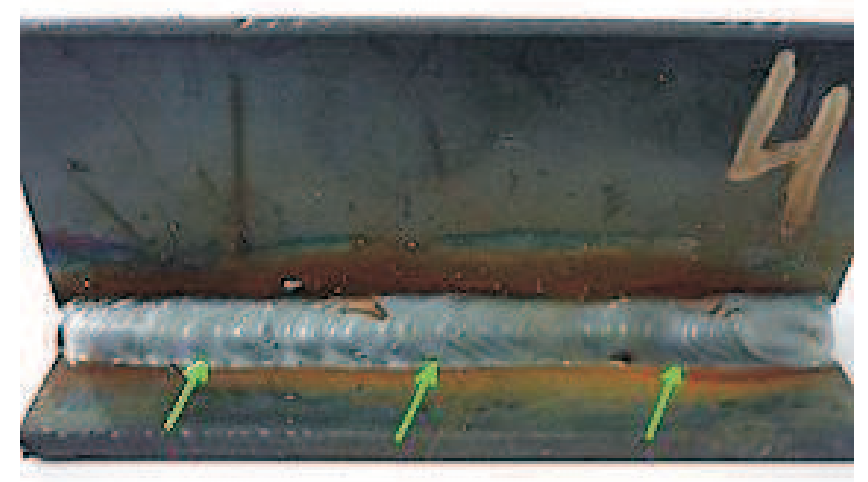

Fig. 4. Corner weld joint with added NPs 


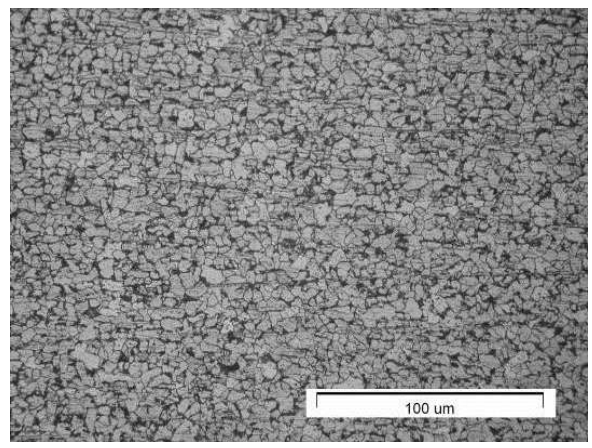

(a)

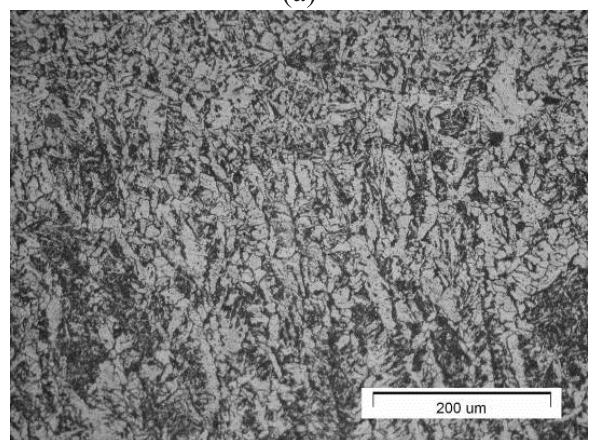

(c)

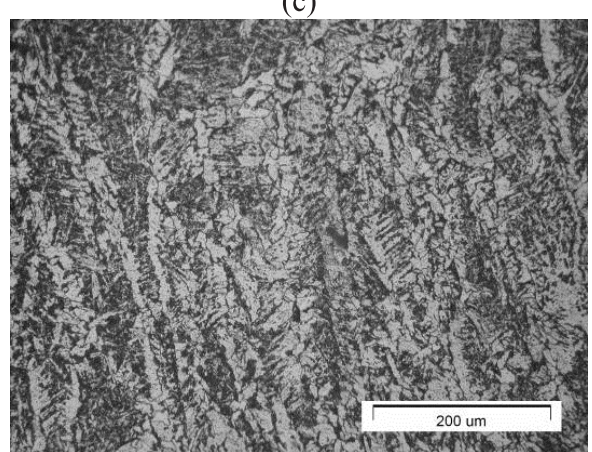

(e)

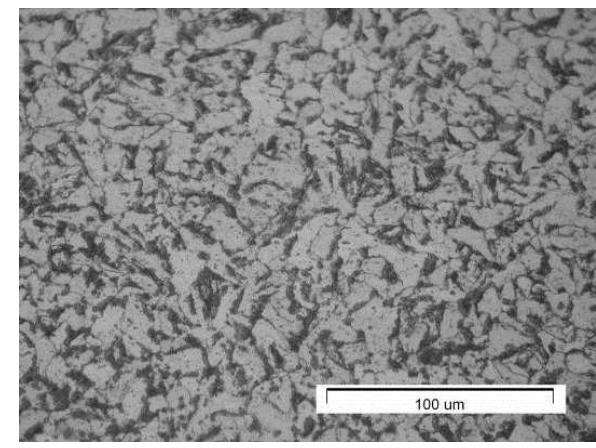

(b)

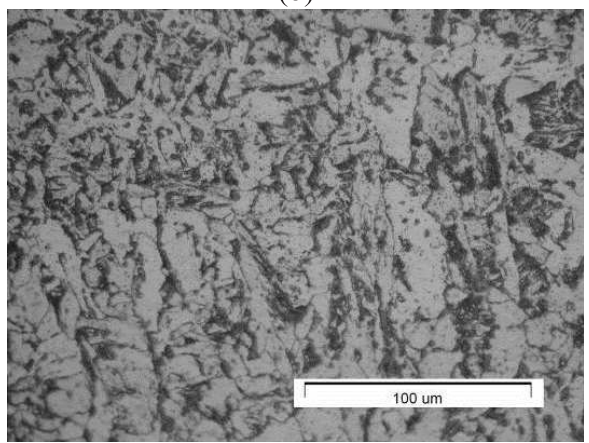

(d)

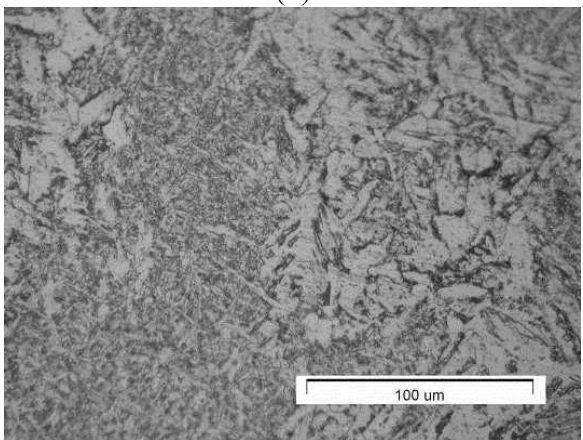

(f)

Fig. 5. (a) BM, $\times 500$; (b) HAZ, $\times 500$; (c) Transition zone $(\mathrm{HAZ} / \mathrm{WZ}), \times 200$; (d) HAZ/WZ, $\times 500$; (e) WZ, $\times 200$; (f) WZ, $\times 500$ 
methodology by grinding, polishing, and etching. The structure of low carbon steel after experimental welding was observed with an Olympus BX41RF optical microscope.

Figure 5(a to f) displays the structure of a weld sample without added NPs. The structure of the Base Metal (BM) is ferrite-perlite and is typical for low carbon rolled steel, Fig. 5(a).

Recrystallization is observed in the Heat Affected Zone (HAZ) when approaching the Weld Zone (WZ), Fig. 5(b). The extent of recrystallization increases with the increase of temperature and a more coarse-grained crystalline structure is observed approaching the weld. The coarse structure in $\mathrm{HAZ}$ results from overheating close to the melting temperature of the BM, Fig. 5(c, d).

Figure 5(e, f) displays Widmanstatten structure with well oriented coarse crystals in the WZ, and Fig. 6(a to d) presents photographs of the struc-

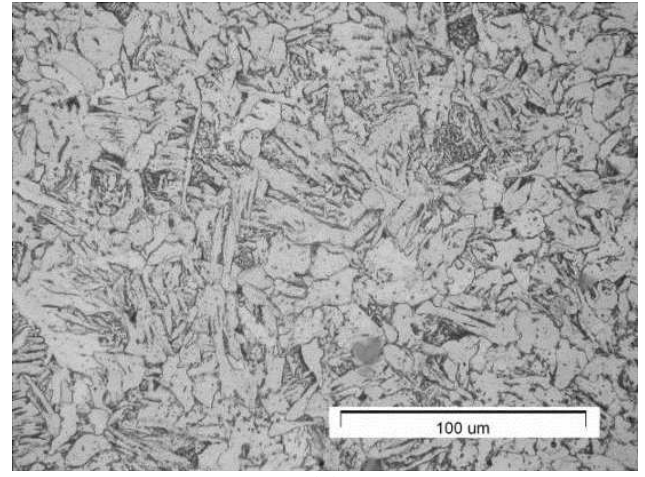

(a)

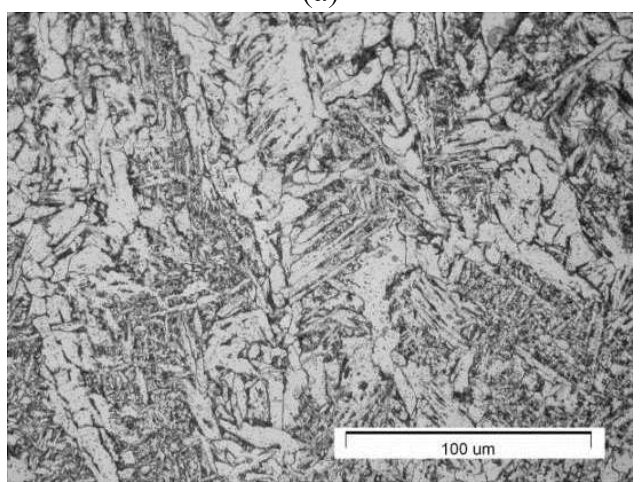

(c)

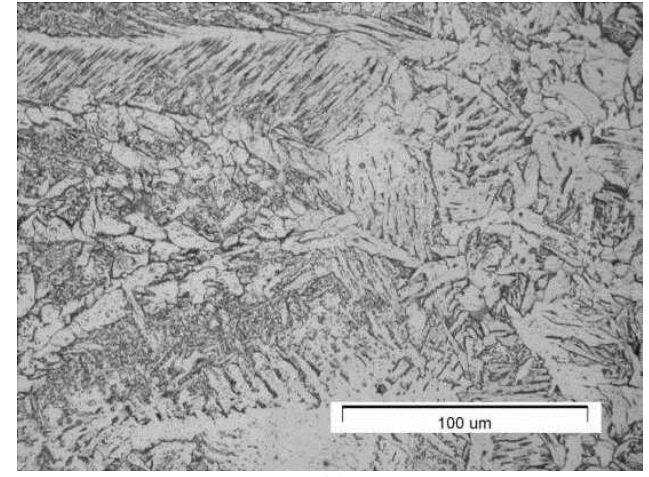

(b)

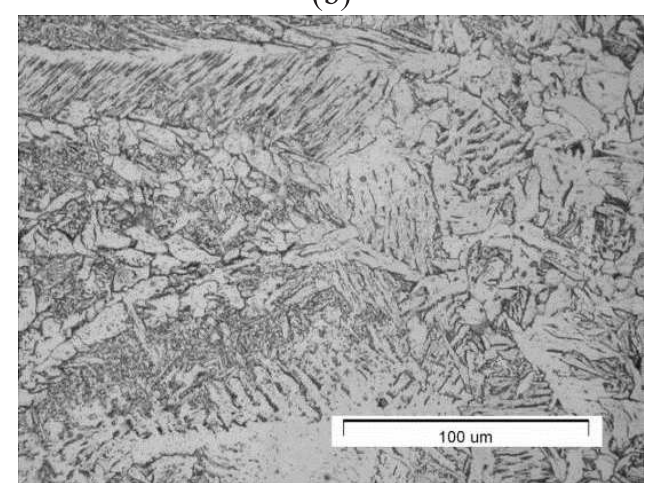

(d)

Fig. 6. (a) HAZ, $\times 500$; (b) WZ/HAZ, $\times 500$; (c) WZ, $\times 500$; (d) WZ, $\times 500$ 
ture obtained by adding NPs in a deliberately created cavity of the sample. The observations on the microstructure of the weld joint do not provide clear evidence of a change compared to the sample without addition of NPs.

The expected positive change in the size of the large ferrite crystals in the weld metal is not observed, as well as no refining of the structure is observed as a whole. This can be explained with the arc "blowing out" a large share of the NPs, thus preventing it from falling into the welding pool, so that the expected effect is not achieved.

\section{EXPERIMENTS FOR APPLICATION OF WELDS THROUGH PRE-APPLICATION OF LAYERS CONTAINING NPS}

The technology for coating steel parts with $\mathrm{Cr}+$ added diamond NPs and their subsequent MIG welding developed in IMSETHAC-BAS was aimed to modification of the weld metal with NPs [17]. For this purpose, a special design of the welded joint has been developed and the sequence of operations for coating and welding has been determined. Metallographic characterization of the changes in the weld metal is performed.

Preliminary studies were performed for galvanic plating of steel with $\mathrm{Cr}$ + added diamond nanoparticles. The composition of the plating electrolyte is $220 \mathrm{~g} / 1 \mathrm{CrO}_{3}$ and $2.2 \mathrm{~g} / \mathrm{l} \mathrm{H}_{2} \mathrm{SO}_{4}$. The used values for current density and duration of the electrochemical process are 30 to $80 \mathrm{~A} / \mathrm{dm}^{2}$ and 15 to 55 min, respectively. After optimization the selected values for current density and duration of electrochemical process are $45 \mathrm{~A} / \mathrm{dm}^{2}$ and $45 \mathrm{~min}$, respectively. It was found that the resulting coatings have higher microhardness and wear resistance, as well as refined grain structure [18-21]. The used diamond nanoparticles, or nanodiamonds (NDs), with size from 1 to $50 \mathrm{~nm}$ were obtained by detonation synthesis (NDDS).

The suggestion of the present approach, in which NPs are introduced by means of the coating into a deliberately separated cavity, is that the NPs would not be "blown out" by the welding arc.

Two types of coated samples are prepared, one with $\mathrm{Cr}$ and the other with $\mathrm{Cr}+\mathrm{ND}$, which are subsequently welded. The samples are made of $4 \mathrm{~mm}$ thick sheet of structural steel S235JR. The plates from which test specimens are made are cleaned and fixed. The preliminary cleaning is necessary in order to avoid any negative effects, e.g., corrosion, oxidation, contamination of the surface, etc. 
The experiments were performed by the method MAG of welding in a protective gas environment (Process 135 according to EN ISO 4063:2009). The protection gases are a major factor influencing the processes in the arc, the transfer of metal, the appearance of the weld, the shape of penetration and the splash formation. In the experiments performed gas mixture M21 with content of $82 \% \mathrm{Ar}$ and $18 \% \mathrm{CO}_{2}$ was used.

The welding electrode selected is solid wire G3Si1 according to BSS EN ISO $14341 / 2009$ with nominal diameter $1.0 \mathrm{~mm}$ and chemical composition (Table 1) appropriate for the used steel S235JR and for achieving the necessary geometry of the weld.

Table 1. Chemical composition of wire G3Si1

\begin{tabular}{|c|c|c|c|c|c|}
\hline $\mathrm{C}$ & $\mathrm{Si}$ & $\mathrm{Mn}$ & $\mathrm{P}$ & $\mathrm{S}$ & $\mathrm{Cu}$ \\
\hline 0.076 & 0.87 & 1.48 & 0.01 & 0.012 & 0.13 \\
\hline
\end{tabular}

The experiments were performed with equipment Kempact Pulse 3000, Fig. 7. It is designed for synergistic welding, MIG/MAG pulse and doublepulse welding. The standard programs are appropriate for different materials. The following parameters of the welding mode are used:

- Wire feed rate, $V_{d}=6 \mathrm{~m} / \mathrm{min}$;

- Current, $I=141 \mathrm{~A}$;

- Voltage, $U=19.7 \mathrm{~V}$;

- Consumption of protection gas $9 \mathrm{l} / \mathrm{min}$.

The welded corner joints are prepared for metallographic analysis accord-

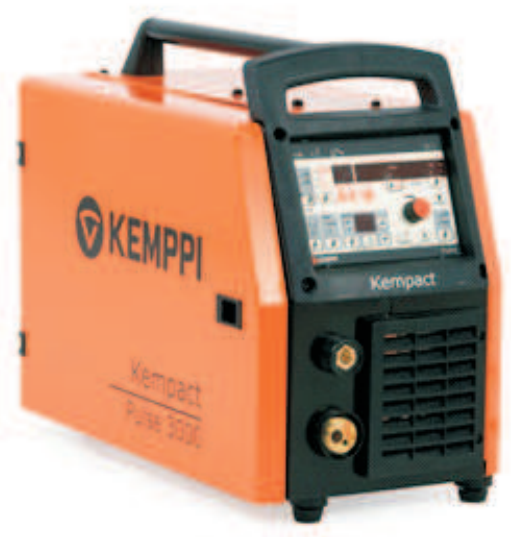

Fig. 7. Kempact Pulse 3000 

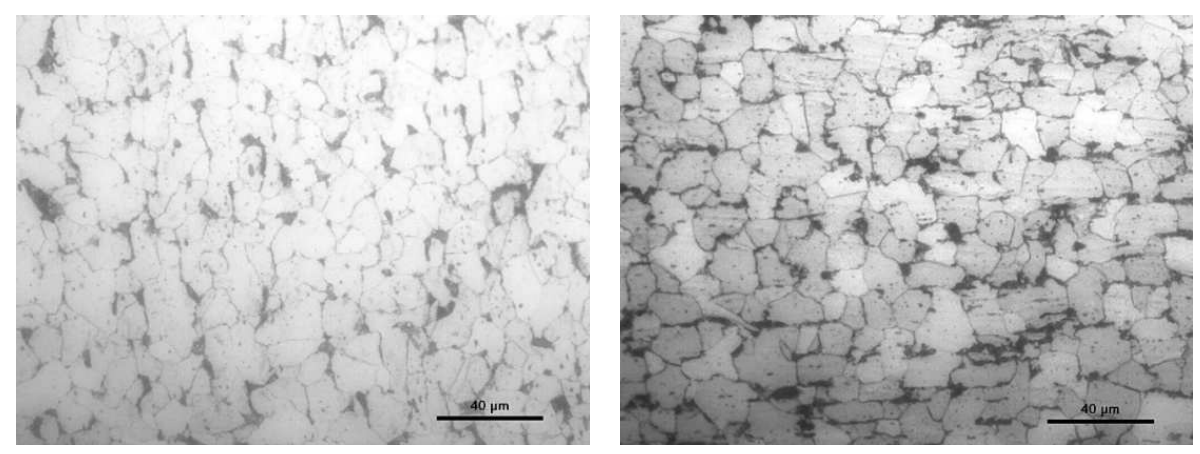

$\mathrm{BM}$
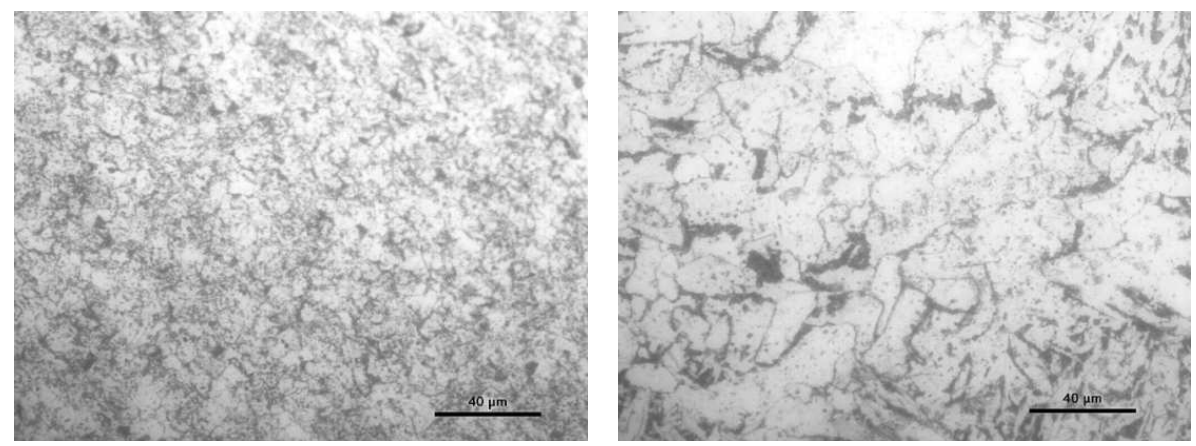

HAZ
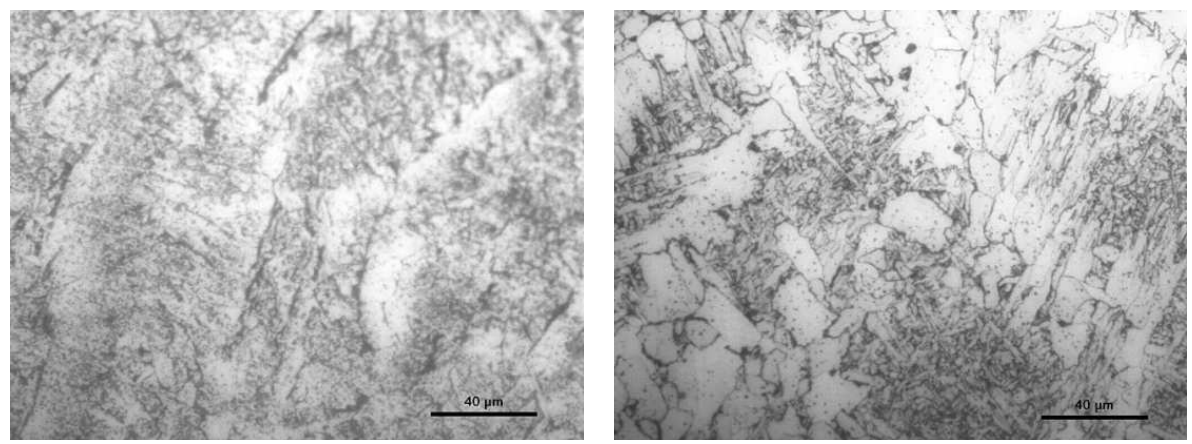

WZ

Fig. 8. Microstructure of BM, HAZ, and WZ

ing to the standard procedure, being wet ground, mechanically polished, and developed using a $4 \%$ solution of $\mathrm{HNO}_{3}$ in ethyl alcohol. The photos in Fig. 8 show the microstructures of the BM, the HAZ and the WZ of the sample with Cr coating - on the left, and the sample with $\mathrm{Cr}+\mathrm{ND}$ coating - on the 


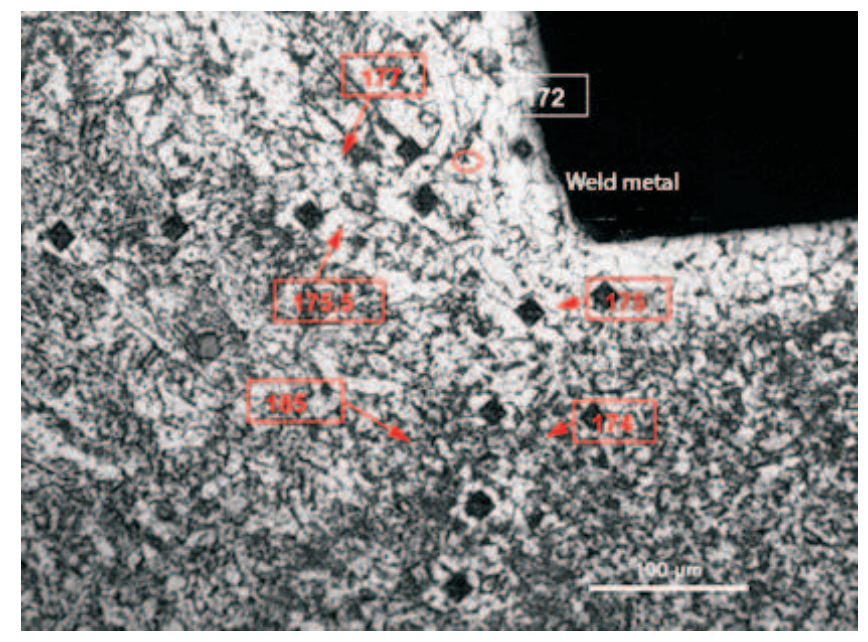

Fig. 9. Values of microhardness, $\mathrm{kg} / \mathrm{mm}^{2}$, in a specimen with $\mathrm{Cr}$ coating

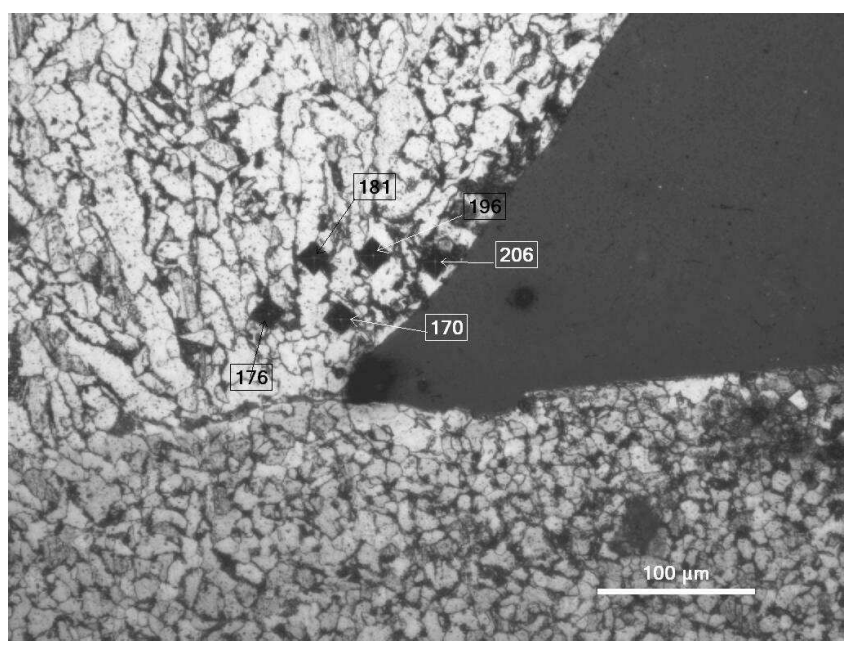

Fig. 10. Values of microhardness, $\mathrm{kg} / \mathrm{mm}^{2}$, in a specimen with $\mathrm{Cr}+\mathrm{ND}$ coating

right. The microstructure of the two samples is ferritic-perlite, as the perlite is distributed mainly along the grain boundaries. Widmanstatten structure is observed in the WZ of the sample with $\mathrm{Cr}+\mathrm{ND}$ coating. In the sample with Cr coating this structure is not well expressed.

The microhardness of the coatings was determined using tester MicroDuromat 4000 with load of $50 \mathrm{~g}$, duration $10 \mathrm{~s}$ and loading speed $10 \mathrm{~g} / \mathrm{s}$ 
on microsections cut out from different samples. The red circle in Fig. 3 shows the location where the microhardness is measured and the values are given in Figs 9 and 10.

Figure 10 shows the region of the welded joint that is assumed to have the highest concentration of diamond NPs. The corresponding region of the sample with Cr coating is shown in Fig. 6.

It is obvious that there is an increase of microhardness with up to $30 \mathrm{~kg} / \mathrm{mm}^{2}$ in the specimen with $\mathrm{Cr}+\mathrm{ND}$ coating. Based on the obtained values of microhardness, we can state that a strip about $70 \mu \mathrm{m}$ wide with a higher concentration of NPs, although not homogeneous, is formed around the root of the weld.

\section{INTRODUCTION OF NPS IN THE LIQUID PHASE BY MEANS OF CORED WIRES}

As pointed out above in the analysis of the possibilities for introduction of NPs into the liquid phase, the process using cored wires seems promising. For the experiments with additions to the liquid phase we selected NPs of TiN coated with oleic acid. Some of the main characteristics of the NPs are given in Table 2.

Table 2. Main characteristics of the used NPs

\begin{tabular}{|c|c|c|c|c|}
\hline Composition & $\begin{array}{c}\text { Specific surface, } \\
\mathrm{m}^{2} / \mathrm{g}\end{array}$ & Specific weight & $\begin{array}{c}\text { Average size, } \\
\mathrm{nm}\end{array}$ & Shape \\
\hline $97.2 \% \mathrm{TiN}$ & $20 \pm 5$ & 5.43 & $50 \pm 5$ & Cubic \\
\hline
\end{tabular}

Titanium nitride, TiN, is steady up to $\sim 2950{ }^{\circ} \mathrm{C}$.

The NPs used are non-flammable, insoluble in water in the range from $20^{\circ} \mathrm{C}$ to $100^{\circ} \mathrm{C}$, and are not radioactive.

The research team has developed a technology for introduction of NPs in the filling of self-protected cored wire intended for preventive overlay welding or restorative surfacing of worn surfaces. The following materials are included in the composition of the cored wire: ferrochrome, ferrosilicon, ferroboron, ferromanganese, calcium carbonate (marble), and about 1.2 to $3 \%$ carbon. After overlay welding the content of $\mathrm{C}$ in the resulting layer is about $0.7 \%$ to 1.0\%. The layer has hardness 64 to 66 HRC.

For better absorption of the NPs from TiN in the process of overlay welding, it is activated by compaction in powdered chromium particles in a planetary mill model FRITSCH PULVERISETTE, type 501. Each of the three carbide 
containers of the mill is filled with $200 \mathrm{~g}$ powder mixture of chromium and titanium nitride in a ratio of 100:1 and $140 \mathrm{~g}$ spherical metal grinding bodies. The activation is performed for 3 minutes. The total amount of mixture treated is $4.6 \mathrm{~kg}$ chromium powder to which $46 \mathrm{~g}$ of nanosized TiN was added. The mixture was added to ferrochrome with chromium content of about 62-66 wt.\% and then to the main amount. The mixture is homogenized and cored self-protective welding wire with NPs of TiN in the filling is manufactured. Experimental overlay welding with $2-3$ layers is performed using both cored wire with NPs and reference cored wire without NPs. The following mode for overlay welding is applied:

- First layer: $U=24 \div 28 \mathrm{~V}, I=350 \mathrm{~A}$;

- Second layer: $I=400 \mathrm{~A}$;

- Third layer: $I=450$ A.

Each subsequent layer is applied after the previous layer is cooled. Specimens for wear resistance testing were water-cut from the welded plates.

The wear resistance of the weld metal is determined by the method used in [22-27] and consisting in measuring the mass wear of the specimens during a number of friction cycles, after which the intensity of wear and the wear resistance were calculated. The comparison according to the indicator "wear resistance" was made under the same test conditions.

The wear resistance test methodology is based on measuring the total mass loss of the test specimen under predetermined fixed conditions of contact between the specimen and the abrasive surface. The conditions of interaction are determined by the load applied to the test specimen, the speed of sliding, the contact surface area, the friction distance traveled, and the type, dimensions and hardness of the abrasive particles. The measured mass wear was used for calculation of the following characteristics: rate of mass wear, intensity of mass wear, and wear resistance.

According to the methodology the experimental studies were performed using a device for accelerated tests with kinematic scheme "thumb-disk".

The methodology was developed in the laboratory of tribology led by Prof. Dr. M. Kandeva at FME, TU-Sofia. It complies with the requirements of the current standards and is consistent with the specifics of the obtained welded layers in experiments with addition of NPs to the liquid phase in processes $111,135,142$ of fusion welding.

The general appearance of the device and the functional scheme for abrasive wear to study the wear of welded layers in conditions of dry friction are shown in Fig. 11.

Engineering Sciences, LVIII, 2021, No. 1 

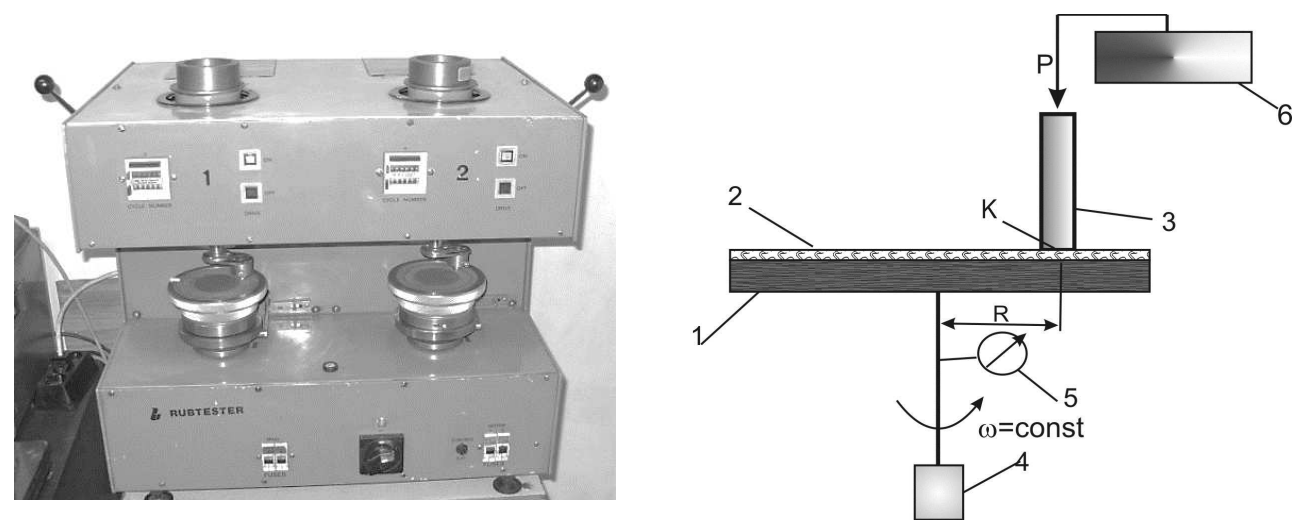

Fig. 11. Device and kinematic scheme "thumb-disk": 1 - rotating disk; 2 - abrasive surface; 3 - tested specimen; $\mathrm{K}$ - tested layer; 4 - drive unit; 5 - tachometer; 6 - loading system

The test specimen, so called "thumb", is mounted stationary, so that the tested layer $(\mathrm{K})$ is oriented to come into contact with the abrasive surface. The loading head is equipped with holders suitable for both types of test specimens used, cylindrical and square-shaped. The horizontal disk rotates around its vertical axis at a constant angular velocity $\omega$ provided by the drive unit. The number of revolutions of the disk is recorded with a tachometer.

The device allows changing the speed of relative sliding between the sample 3 and the disk 1 in two ways: changing the angular velocity $\omega$ from the control unit, or changing the distance $R$ between the axis of rotation of the horizontal disk and the axis of the specimen.

The abrasive surface is made of impregnated carborundum with hardness at least $60 \%$ higher than the hardness of the tested layers.

The parameters of the experimental study for abrasive wear are:

- Nominal contact pressure $P_{a}\left[\mathrm{~N} / \mathrm{cm}^{2}\right]$, which is the normal loading $P$ per unit nominal contact surface $A_{a}$ where:

$$
p_{a}=\frac{P}{A_{a}} .
$$

The size of the nominal contact pressure can be adjusted by changing the load $P$ and/or by changing the nominal contact surface $A_{a}$.

- Average velocity of sliding friction $V$, which is the velocity of the mass center of the contact area, is calculated by the formula:

$$
V=\omega \cdot R=\frac{\pi \cdot n}{30} R
$$


where $\omega[\mathrm{rad} / \mathrm{s}]$ is angular velocity and $n[\mathrm{rpm}]$ is revolutions per minute.

The size of the sliding speed is changed by adjusting the distance $R$ to the axis of rotation of the disk.

The device is designed for testing both main types of samples - cylindrical and square-shaped. The cylindrical specimens are intended for tests of welded layers on relatively thicker parts (about $20 \mathrm{~mm}$ ) obtained, for example, by processes 111, 135 and 136, Fig. 12.

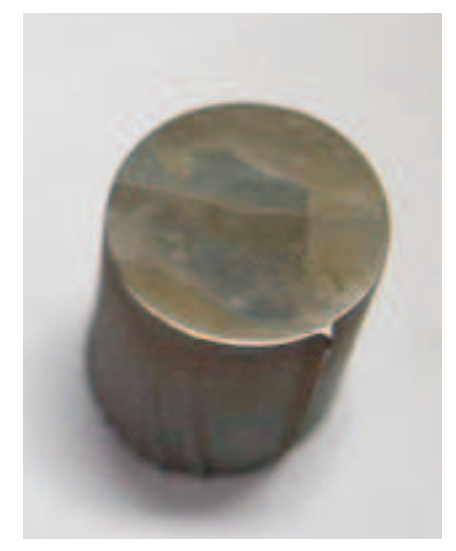

Fig. 12. Water abrasive cut cylindrical specimen

Table 3 presents the values of the minimum and maximum sizes of the tested specimens, as well as Table 4 presents data on the range of variation of the normal load, the sliding speed, the nominal contact area and the nominal friction contact pressure.

The methodology of determining the wear characteristics is based on measuring the mass wear of the specimens after travelling a certain friction path. The parameters preset are loading, sliding velocity, type of abrasive. The following characteristics of the mass wear are calculated: wear rate, wear intensity, wear resistance, relative wear resistance, and relative variation of wear resistance.

The following operations are carried out:

- The specimen is cleaned of mechanical and organic contamination and is dried with ethyl alcohol to prevent the electrostatic effect;

- The mass of the specimen $m_{0}$, g, is measured on electronic scale accurate to $0.1, \mathrm{~g}$;

- The specimen is attached to the loading head by means of a holder corresponding to its geometry; 
Table 3. Sizes of the tested specimens

\begin{tabular}{|l|l|}
\hline \multicolumn{2}{|c|}{ Cylinder } \\
\hline Minimum radius & $2.5 \mathrm{~mm}$ \\
\hline Maximum radius & $7.5 \mathrm{~mm}$ \\
\hline Height & 20 to $25 \mathrm{~mm}$ \\
\hline
\end{tabular}

Table 4. Ranges of variation of the values of the nominal loading $P$, the sliding velocity $V$, the nominal contact surface $A_{a}$, and the nominal contact pressure $P_{a}$

\begin{tabular}{|l|c|l|c|}
\hline \multicolumn{2}{|c|}{ Normal loading, $P[\mathrm{~N}]$} & \multicolumn{2}{c|}{ Average sliding velocity, $V[\mathrm{~cm} / \mathrm{s}]$} \\
\hline Minimum & 1.2 & Minimum & 33.4 \\
\hline Maximum & 50 & Maximum & 89 \\
\hline \multicolumn{2}{|l|}{ Nominal surface area, $A_{a}\left[\mathrm{~mm}^{2}\right]$} & Nominal contact pressure, $P_{a}\left[\mathrm{~N} / \mathrm{cm}^{2}\right]$ \\
\hline Minimum & 6.25 & Minimum & 0.5 \\
\hline Maximum & 225 & Maximum & 800 \\
\hline
\end{tabular}

- The predetermined normal loading $P$ is set. The sliding velocity is set by fixing the distance between the axis of rotation of the disk and the mass center of the specimen;

- The process of wear is realized by travelling a certain friction path $L$, which corresponds to a certain number of friction cycles set by the device counter;

- The mass of the specimen $m(L)$ is measured after travelling the path $L$.

The characteristics of the mass wear are calculated:

- Mass wear $M, \mathrm{mg}$, is the mass stripped from the surface layer after travelling a certain friction path:

$$
m=m_{o}-m(L)
$$

- Rate of mass wear $\gamma, \mathrm{mg} / \mathrm{min}$, is the mass stripped for unit time of friction:

$$
\gamma=\frac{m}{t}
$$

- Wear intensity $i, \mathrm{~m} / \mathrm{m}$, is the wear of the specimen for unit path of friction. The intensity presented through the linear wear is determined by the formula:

$$
i=\frac{m}{\rho \cdot A_{a} L} .
$$

The wear intensity is dimensionless quantity;

- The wear resistance $I, \mathrm{~m} / \mathrm{m}$, is the reciprocal value of wear intensity:

$$
I=\frac{1}{i}=\frac{\rho \cdot A_{a} L}{m} ;
$$


- The relative wear resistance $E_{i, e}$ is calculated by the formula:

$$
E_{i, e}=\frac{I_{i}}{I_{e}}=\frac{I_{i}}{I_{o}},
$$

where $I_{i}$ is wear resistance of the tested specimen, $I_{e}$ is wear resistance of the reference specimen and both values are determined at the same conditions of wear. The base material on which the welded layers are obtained is taken as a reference. If the reference specimen is denoted as No 0 , then $I_{e}=I_{0}$.

The relative change of the wear resistance $\Delta E_{i, e} \%$ is the ratio of wear resistance of the worn specimen to the wear resistance of the reference specimen in percent, and it is determined by the formula:

$$
\Delta E_{i, e}=\frac{I_{i}-I_{e}}{I_{e}} .100=\frac{I_{i}-I_{o}}{I_{o}} .100, \% .
$$

The results from wear resistance testing of Specimen No 1 modified with NPs are given in Table 5, and the results from wear resistance test of the non-modified reference Specimen No 0 in Table 6.

Table 5. Parameters of wear resistance of Specimen No 1

\begin{tabular}{|c|c|c|c|}
\hline$N$ & 200 & 400 & 600 \\
\hline$t[\mathrm{~min}]$ & 0.96 & 1.92 & 2.88 \\
\hline$L[\mathrm{~m}]$ & 46.4 & 92.8 & 139.2 \\
\hline \multicolumn{4}{|c|}{ Specimen No 1.1} \\
\hline$m[\mathrm{mg}]$ & 8.2 & 12.1 & 15.7 \\
\hline$\gamma=m / t[\mathrm{mg} / \mathrm{min}]$ & 8.5 & 6.3 & 5.45 \\
\hline$i=m / \rho A_{a} L$ & $0.45 .10^{-6}$ & $0.33 .10^{-6}$ & $0.29 .10^{-6}$ \\
\hline$I=1 / i$ & $2.23 .10^{6}$ & $3.02 .10^{6}$ & $3.5 .10^{6}$ \\
\hline \multicolumn{4}{|c|}{ Specimen No 1.2} \\
\hline$m[\mathrm{mg}]$ & 7.1 & 11.6 & 15.5 \\
\hline$\gamma=m / t[\mathrm{mg} / \mathrm{min}]$ & 7.4 & 6.04 & 5.4 \\
\hline$i=m / \rho A_{a} L$ & $0.39 .10^{-6}$ & $0.32 .10^{-6}$ & $0.28 .10^{-6}$ \\
\hline$I=1 / i$ & $2.57 .10^{6}$ & $3.1 .10^{6}$ & $3.5 .10^{6}$ \\
\hline
\end{tabular}

The specimen modified with NPs exhibits greater repeatability of the testing results, which can be explained by the homogenizing effect of the NPs on the structure of the weld metal. Metallographic studies for better interpretation of the results are forthcoming.

The relative wear resistance of the specimens modified with NPs of TiN was increased about 1.4-fold compared to the reference specimen. 
Table 6. Parameters of wear resistance of Specimen No 0

\begin{tabular}{|c|c|c|c|}
\hline$N$ & 200 & 400 & 600 \\
\hline$t[\mathrm{~min}]$ & 0.96 & 1.92 & 2.88 \\
\hline$L[\mathrm{~m}]$ & 46.4 & 92.8 & 139.2 \\
\hline \multicolumn{4}{|c|}{ Specimen No 0.1} \\
\hline$m[\mathrm{mg}]$ & 6.7 & 12.4 & 12.4 \\
\hline$\gamma=m / t[\mathrm{mg} / \mathrm{min}]$ & 7.0 & 6.5 & 6.5 \\
\hline$i=m / \rho A_{a} L$ & $0.37 .10^{-6}$ & $0.34 .10^{-6}$ & $0.34 .10^{-6}$ \\
\hline$I=1 / i$ & $2.33 .10^{6}$ & $2.95 .10^{6}$ & $2.95 .10^{6}$ \\
\hline \multicolumn{4}{|c|}{ Specimen No 0.2} \\
\hline$\gamma[\mathrm{mg}]$ & 14.9 & 21.9 & 31.2 \\
\hline$\gamma=m / t[\mathrm{mg} / \mathrm{min}]$ & 15.5 & 11.4 & 10.8 \\
\hline$i=m / \rho A_{a} L$ & $0.82 .10^{-6}$ & $0.6 .10^{-6}$ & $0.57 .10^{-6}$ \\
\hline$I=1 / i$ & $1.23 .10^{6}$ & $1.67 .10^{6}$ & $1.76 .10^{6}$ \\
\hline
\end{tabular}

\section{CONCLUSIONS}

A methodology for electrochemical deposition of chrome coatings modified with diamond nanoparticles on steel has been developed.

After optimization, the composition of the electrolyte for electrochemical deposition of chromium with diamond nanoparticles on T-shaped welded steel joints was determined. The deposition was carried out at concentration of diamond nanoparticles $25 \mathrm{~g} / \mathrm{l}$, current density $45 \mathrm{~A} / \mathrm{dm}^{2}$, duration $45 \mathrm{~min}$, and temperature of electrolyte $50 \div 550{ }^{\circ} \mathrm{C}$.

Methodology has been developed for overlay welding on T-shaped welded steel joints with coatings of $\mathrm{Cr}$ only and $\mathrm{Cr}+\mathrm{ND}$.

It was found that the microstructure of the specimens taken from both joints is ferritic-pearlitic, as Widmanstatten structure is observed in the WZ of the specimen with $\mathrm{Cr}+\mathrm{ND}$ coating but in the specimen with $\mathrm{Cr}$ coating it is not well expressed.

Increase of microhardness with up to $30 \mathrm{~kg} / \mathrm{mm}^{2}$ was found in the zone of introduction of ND of the specimen with $\mathrm{Cr}+\mathrm{ND}$ coating. Based on the values of microhardness obtained, it can be stated that a strip with width $\sim 70 \mu \mathrm{m}$ is formed around the root of the overlay weld with a higher concentration of NPs, although not equally homogeneous.

The developed technology for introduction of NPs in the filling of cored selfprotective wire intended for preventive overlay welding gives promising results. After surfacing with modified cored wire, the hardness of the welded layer is 
64-66 HRC. The relative wear resistance of the samples modified with NPs of TiN was increased about 1.4-fold compared to that of the control sample.

\section{REFERENCES}

[1] A. J. Novinnooz, H. Seyedi, And M. M. Larigani, Microhardness study of $\operatorname{Ti}(\mathrm{C}, \mathrm{N})$ films by Hallow Cathode Discharge Gun, Journal of Achievements in Materials and Manufacturing Engineering (2006) 14 59-63.

[2] M. I. Jones And I. R. MCColl, Effect of substrate preparation condition of TiN coating by RF sputtering, Surface and Coatings Technology (2000) 132 143-151.

[3] A. J. Novinrooz, N. Afshari, And H. Seyedi, Improvement of hardness and corrosion resistance of SS-420 by $\mathrm{Cr}+\mathrm{TiN}$ coatings, Journal of Achievments in Materials and Manufacturing Engineering (2007) 23 (1).

[4] A. N. Cherepanov et al., On the use of nanopowders of refractory compounds in welding and processing of metals and alloys, Heavy Engineering (2008) 4 (2) $25-26$ (in Russian).

[5] M. Tongov, Welding, Part I, Processes, Softtrade (2009), ISBN 978-954-334096-5 (in Bulgarian).

[6] V. Petkov, P. Tashev, R. Lazarova, S. Vulkanov, and N. Gidikova, Overlay welding of steel galvanized with chromium and nanoparticles, Nanoscience \& Nanotechnology (2013) 13 199-201, ISSN 1313-8995.

[7] V. A. Lenivkin, N. G. Dyurgerov, and H. N. Sagirov, Technological properties of welding arc in protective gases, Moscow, Machine building (1989) 264 (in Russian).

[8] B. E. Paton, A. M. Makara, I. K. Pokhodnia et al., Weldability of structural steels subjected to refining remelting, Automatic Welding (1974) 6 1-4 (in Russian).

[9] S. G. PARshin, Electric arc welding with use of activating fluxes, Samara Scientific Center of the Russian Academy of Sciences (2006) 380 (in Russian).

[10] S. G. PARshin and S. S. PARshin, Activated welding wire. MPK7 V23K 35/365, V23K 35/04. Patent of the R.F. No 2294272/01.11.2005, Bul. No 6/27.02.2007, Production based on the development of nanostructured electrode materials with composite coating of high fineness activating fluxes (in Russian).

[11] S. PARshin And G. Bürkner, Technology of MIG welding of steel using composite electrode materials with activated surface, Welding Production (2011) 10 27-31, UDC 621.791.75, Machine Building Publishing Center (Moscow), ISSN 0491-6441 (in Russian).

[12] Y. Y. Dolmatov, T. Fujimura, G. K. Borkat, E. A. Orlova, and M. V. Veretennikova, Preparation of wear-resistant chromium coatings using different types of nanodiamonds, Powder Metallurgy and Metal Ceramics (2003) 42 $(11-12)$. 
[13] N. V. Mandich and Y. K. Dennis, Codeposition of nanodiamonds with Chromium, Metal Finishing (2001) 117.

[14] Viet-Hue Nguen, Thi-Nam Hoang, Ngoe-Thong Nguyen, Sik-Chol Kwon, Man-Kim, and Joo-Yul LeE, Cr/nanodiamond composite plating with cobalt cation additive, Transactions of Nonferrous Metal Society of China (2009) 19 975-978.

[15] I. Petrov, P. Detkov, A. Drovosekov, M. Ivanov, T. Tyler, O. ShenDerova, N. Voznekova, Y. Toporov, And D. Schulz, Nickel galvanic coatings co-deposited with fractions of detonation nanodiamond, Diamond and Related Materials (2006) 15 2035-2038.

[16] P. Tashev, S. Valkanov, P. Petrov, and E. Balabanova, Microstructure of gas metal arc welded carbon steel with nanoparticles, Nanoscience $\mathbb{E}$ Nanotechnology (2013) 13 199-201, ISSN 1313-8995.

[17] P. Tashev, R. Lazarova, S. Valkanov, R. Dimitrova, V. Petkov, Examination of overlaid weld cladding with addition of nanosized diamond particles, Mechanics Transport Communications, art ID: 773, (2013) 11 (1) article No 0773, ISSN 1312-3827.

[18] N. Gidikova, M. Sulowski, V. Petkov, R. Valov, and G. Cempura, Composite coatings of chromium and nanodiamond particles on steel, Arch. Metall. Mater. (2017) 62 (4) 2421-2424, ISSN 1733-3490, DOI: 10.2478.

[19] V. PetKov and R. Valov, Effects of diamond nanoparticles on the microstructure, hardness and corrosion resistance of chromium coatings, American Journal of Chemical Engineering (2020) 8 (6) 125-130, ISSN 2330-8605 (Print), ISSN 2330-8613 (Online).

[20] V. Petkov, R. Valov, M. Witkowska, M. Madej, G. Cempura, and M. SuŁowski, Sintered steels coated with a chromium layer doped with diamond nanoparticles, Arch. Metall. Mater. (2019) 64 (4) 1633-1638, DOI: 10.24425/amm. 2019.130137.

[21] V. Petkov, P. Tashev, N. Gidikova, M. Kandeva, and R. Valov, Wear resistant chromium coating with diamond nanoparticles upon an arc deposited layer, Journal of the Balkan Tribological Association (2015) 21 (1) 134-140.

[22] ASTM G 99-95a, Standard test method for wear testing with a pin-on-disk apparatus.

[23] DIN 50324 Tribology; testing of friction and wear model test for sliding friction of solids (ball-on-disc system).

[24] BSS 14289-77 Test method for abrasive wear by friction on fixed abrasive particles (in Bulgarian).

[25] M. Kandeva, Contact approach in engineering tribology, TU-Sofia (2015) 505 (in Bulgarian).

[26] I. Pechev And M. Kandeva, Characterizing of Composite Coatings deposited through super sound stream (HVOF-process), Tribological Journal BULTRIB, TU-Sofia (2012) 2 187-197. 
[27] M. Kandeva And B. Ivanova, Abrasive Wear and Wear-Resistance of High Strength Cast Iron Containing Sn Microalloy, International Journal of the Balkan Tribological Association (2013) 4 547-559.

Received January 13, 2021

Engineering Sciences, LVIII, 2021, No. 1 